Pacific Journal of Mathematics

INTEGRATED ORTHONORMAL SERIES 


\title{
INTEGRATED ORTHONORMAL SERIES
}

\author{
JAMES R. MCLAUGHLIN
}

Throughout this paper the author defines

$$
F_{\alpha}(t)=\sum_{m=1}^{\infty}\left|\Phi_{m}(t)\right|^{\alpha}=\sum_{m=1}^{\infty}\left|\int_{a}^{t} \varphi_{m}(x) d x\right|^{\alpha}
$$

where $0<\alpha \leqq 2, a \leqq t \leqq b$, and $\left\{\varphi_{m}\right\}$ is a sequence in $L^{1}[a, b]$, usually orthonormal. In this paper, $F_{\alpha}(t)$ is studied for the Haar, Walsh, trigonometric, and general orthonormal sequences. For instance, it is proved that for the Haar system $F_{\alpha}(t)$ satisfies a Lipschitz condition of order $\alpha / 2$ in $[0,1]$ and that this result is best possible for any complete orthonormal sequence. An application is also given regarding the absolute convergence of Walsh series.

Previously, Bosanquet and Kestelman essentially proved [3, p. 91]

Theorem A. Let $\left\{\Phi_{m}\right\}$ be orthonormal. Then the Fourier coefficients of every absolutely continuous function are absolutely convergent if and only if $F_{1}(t) \in L^{\infty}[a, b]$.

Also, applying Parseval's equality to the characteristic function of $[a, t]$, we obtain

THEOREM B. Let $\left\{\varphi_{m}\right\}$ be orthonormal. Then $\left\{\varphi_{m}\right\}$ is complete in $L^{2}[a, b]$ if and only if $F_{2}(t)=t-a, a \leqq t \leqq b$.

For certain systems, such as the Haar system, the following extension of Theorem A is possible.

THEOREM 1. Assume $\left\{\varphi_{m}\right\}$ is orthonormal, $\Phi_{m}(t)$ has constant sign on $[a, b]$ for each $m=1,2, \cdots$, and $\Sigma\left|\Phi_{m}(b)\right|<\infty$. Then the Fourier coefficients of every absolutely continuous function $f(t)$, such that $f^{\prime}(t) \in L^{p}$, are absolutely convergent if and only if $F_{1}(t) \in L^{q}, 1 \leqq p \leqq \infty$, $p^{-1}+q^{-1}=1$.

Proof. Necessity. Integrating by parts we obtain

$$
\int_{a}^{b} f^{\prime}(t) \sum_{m=1}^{\infty}\left|\Phi_{m}(t)\right| d t
$$

exists for every $f^{\prime} \in L^{p}$. Hence, $F_{1}(t) \in L^{q}[7$, p. 166].

Sufficiency. By Hölder's inequality 


$$
\sum_{m=1}^{N}\left|\int_{a}^{b} f^{\prime}(t) \Phi_{m}(t) d t\right| \leqq \int_{a}^{b}\left|f^{\prime}(t)\right| \sum_{1}^{N} \Phi_{m}(t) \mid d t \leqq\left\|f^{\prime}\right\|_{p}\left\|F_{1}\right\|_{q} \cdot
$$

If an orthonormal sequence $\left\{\varphi_{m}\right\}$ is not complete we still obtain $F_{2}(t)$ continuous since the "completed" series converges to a continuous function and hence (i.e. by Dini's theorem) the convergence must be uniform. In fact, we have

THEOREM 2. If $\left\{\varphi_{m}\right\}$ is orthonormal, then $F_{2}(t) \in \operatorname{Lip}(1 / 2)$.

Proof. Let $x, y \in[a, b]$. Using Bessel's inequality, we obtain

$$
\begin{aligned}
\left|F_{2}(x)-F_{2}(y)\right|= & \left|\sum_{m=1}^{\infty}\left[\Phi_{m}(x)\right]^{2}-\left[\Phi_{m}(y)\right]^{2}\right| \\
\leqq & \sum_{m=1}^{\infty}\left|\Phi_{m}(x)-\Phi_{m}(y)\right|\left\{\left|\Phi_{m}(x)\right|+\left|\Phi_{m}(y)\right|\right\} \\
\leqq & \left\{\sum_{m=1}^{\infty}\left[\Phi_{m}(x)-\Phi_{m}(y)\right]^{2} \sum_{m=1}^{\infty}\left[\Phi_{m}(x)\right]^{2}\right\}^{1 / 2} \\
& +\left\{\sum_{m=1}^{\infty}\left[\Phi_{m}(x)-\Phi_{m}(y)\right]^{2} \sum_{m=1}^{\infty}\left[\Phi_{m}(y)\right]^{2}\right\}^{1 / 2} \\
\leqq & 2|b-a|^{1 / 2}|x-y|^{1 / 2} .
\end{aligned}
$$

REMARK 1. This result is best possible in the following sense: For every $\varepsilon>0$ if we set $\varphi_{1}(x)=(1-x)^{(\varepsilon-1) / 2}, 0 \leqq x<1$, then $\varphi_{1} \in L^{2}[0,1]$ but $\left[\Phi_{1}(t)\right]^{2} \notin \operatorname{Lip}(1 / 2+\varepsilon)$.

REMARK 2. It would be interesting to know if $F_{2}(t)$ is absolutely continuous and if $F_{2}^{\prime}(t) \in L^{2}$ for any orthonormal sequence $\left\{\mathscr{\rho}_{m}\right\}$.

Theorem 3. For any complete orthonormal system $\left\{\varphi_{m}\right\}, F_{\alpha}(t) \in$ $\operatorname{Lip}(\alpha / 2+\varepsilon)$ for any $\varepsilon>0$.

Proof. Let $t \in[a, b]$. By Parseval's equality

$$
\left[F_{\alpha}(t)\right]^{1 / \alpha} \geqq\left[F_{2}(t)\right]^{1 / 2}=(t-a)^{1 / 2}, 0<\alpha \leqq 2,
$$

since for any nonnegative sequence $\left\{a_{m}\right\},\left[\Sigma a_{m}^{\alpha}\right]^{1 / \alpha}$ is a non-increasing function of $\alpha$ for $\alpha>0$.

We will now determine which Lipschitz class $F_{\alpha}(t)$ belongs to for the Haar, Walsh, and trigonometric systems.

Definition. If $0<\alpha \leqq 1$, set

$$
N_{\alpha}(f)=\sup |f(x)-f(y)||x-y|^{-\alpha} \text { for } x \neq y \text { and } x, y \in[a, b] \text {. }
$$

Lemma 1. Let $\alpha>0$ and $0<\alpha-\beta \leqq 1$. If 


$$
\sum_{m=1}^{n} N_{\alpha}\left(f_{m}\right)=O\left(n^{\beta}\right)
$$

and

$$
\sum_{m=n}^{\infty}\left\|f_{m}\right\|_{\infty}=O\left(n^{\beta-\alpha}\right),
$$

then

$$
f(t)=\sum_{m=1}^{\infty} f_{m}(t) \in \operatorname{Lip}(\alpha-\beta) .
$$

Proof. Let $2^{-n-1}<h \leqq 2^{-n}$. Then

$$
\begin{aligned}
|f(t+h)-f(t)| & \leqq \sum_{m=1}^{\infty}\left|f_{m}(t+h)-f_{m}(t)\right|=\sum_{m=1}^{2^{n}}+\sum_{m=2^{n}+1}^{\infty}=P+Q . \\
P & =O\left[h^{\alpha} \sum_{m=1}^{2^{n}} N_{\alpha}\left(f_{m}\right)\right]=O\left(h^{\alpha-\beta}\right), \\
Q & =O\left[\sum_{m=2^{n}+1}^{\infty}\left\|f_{m}\right\|_{\infty}\right]=O\left(h^{\alpha-\beta}\right) .
\end{aligned}
$$

LEMMA 2. (a) If $\sum_{m=2^{n+1}}^{2^{n+1}}\left|a_{m}\right| m^{\alpha}=O\left(2^{n \beta}\right)$, then

$$
\sum_{m=n}^{\infty}\left|a_{m}\right|=O\left(n^{\beta-\alpha}\right), \beta-\alpha<0 \text {. }
$$

(b) If $\sum_{m=2^{n}+1}^{2^{n+1}}\left|a_{m}\right|=O\left(2^{n \beta}\right)$, then $\sum_{m=1}^{n}\left|a_{m}\right| m^{\alpha}=O\left(n^{\alpha+\beta}\right), \alpha+\beta>0$.

Proof. Straightforward.

Lemma 3. Let $0<\gamma \leqq 1$ and suppose $f \in \operatorname{Lip} \gamma$.

(a) If $0<\alpha \leqq 1,|f|^{\alpha} \in \operatorname{Lip}(\alpha \gamma)$.

(b) If $\alpha>1,|f|^{\alpha} \in \operatorname{Lip} \gamma$.

Proof. We may assume $f(t) \geqq 0$ because

$$
|| f(t+h)|-| f(t)|| \leqq|f(t+h)-f(t)| \cdot
$$

Part (a). Since $|x+y|^{\alpha} \leqq|x|^{\alpha}+|y|^{\alpha}, 0<\alpha \leqq 1$, we obtain

$$
\left|f^{\alpha}(t+h)-f^{\alpha}(t)\right| \leqq|f(t+h)-f(t)|^{\alpha}=O\left(h^{\alpha \tau}\right) \text {. }
$$

Part (b). Since $\left|x^{\alpha}-y^{\alpha}\right| \leqq|| \alpha t^{\alpha-1} \|_{\infty}|x-y|, \alpha \geqq 1$, it follows that

$$
\left|f^{\alpha}(t+h)-f^{\kappa}(t)\right| \leqq\left|\alpha f^{\alpha-1}(t) \|_{\infty}\right| f(t+h)-f(t) \mid=O\left(h^{r}\right) .
$$

THEOREM 4. Let $0<\gamma \leqq 1$ and assume $f \in \operatorname{Lip} \gamma$ and is of period $b-a$.

(a) If $0<\alpha \leqq 1,0<\alpha \gamma-\hat{o} \leqq 1$, and

$$
\sum_{m=1}^{n}\left|a_{m}\right| m^{\alpha \gamma}=O\left(n^{j}\right)
$$


then

$$
f_{\alpha}(t)=\sum_{m=1}^{\infty} a_{m}|f(m t)|^{\alpha} \in \operatorname{Lip}(\alpha \gamma-\delta)
$$

(b) If $\alpha>1,0<\gamma-\delta \leqq 1$, and

$$
\sum_{m=1}^{n}\left|a_{m}\right| m^{r}=O\left(n^{\delta}\right)
$$

then

$$
f_{\alpha}(t)=\sum_{m=1}^{\infty} a_{m}|f(m t)|^{\alpha} \in \operatorname{Lip}(\gamma-\delta)
$$

Proof. Part (a). By hypothesis and Lemma 3 (a)

$$
\sum_{m=1}^{n} N_{\alpha \gamma}\left[a_{m}|f(m t)|^{\alpha}\right]=O\left(\sum_{1}^{n}\left|a_{m}\right| m^{\alpha \gamma}\right)=O\left(n^{\gamma}\right) .
$$

Also, by Lemma 2 (a), if $0<\alpha \gamma-\delta$, then

$$
\sum_{m=n}^{\infty}\left\|a_{m}|f(m t)|^{\alpha}\right\|_{\infty}=O\left(\sum_{n}^{\infty}\left|a_{m}\right|\right)=O\left(n^{\delta-\alpha r}\right)
$$

and so our result follows by Lemma 1.

Part (b). By hypothesis and Lemma 3j(b)

$$
\sum_{m=1}^{n} N_{\gamma}\left[a_{m}|f(m t)|^{\alpha}\right]=O\left(\sum_{1}^{n}\left|a_{m}\right| m^{\gamma}\right)=O\left(n^{\delta}\right) .
$$

Also, by Lemma 2 (a), if $0<\gamma-\delta$, then

$$
\sum_{m=n}^{\infty}\left\|a_{m}|f(m t)|^{\alpha}\right\|=O\left(\sum_{n}^{\infty}\left|a_{m}\right|\right)=O\left(n^{\delta-\gamma}\right)
$$

and so our result again follows from Lemma 1.

THEOREM 5. Let $0<\alpha \leqq 2$ and assume $\varphi \in L^{\infty}[a, b], \varphi_{m}(x)=\varphi(m x)$, and $\Phi_{1}(t)$ is of period $b-a$. If

$$
\sum_{m=1}^{n}\left|b_{m}\right|=O\left(n^{\beta}\right), 0<\alpha-\beta<1
$$

then

$$
G_{\alpha}(t)=\sum_{m=1}^{\infty} b_{m}\left|\Phi_{m}(t)\right|^{\alpha} \in \operatorname{Lip}(\alpha-\beta)
$$

Proof. $\Phi_{m}(t)=m^{-1} \Phi_{1}(m t)$ and so 


$$
G_{\alpha}(t)=\sum_{m=1}^{\infty} b_{m} m^{-\alpha}\left|\Phi_{1}(m t)\right|^{\alpha} .
$$

Now let $\gamma=1$ and $a_{m}=b_{m} m^{-\alpha}$ in Theorem 4. Then, if $0<\alpha \leqq 1$, our result follows by Theorem 4 (a) with $\delta=\beta$.

If $\alpha>1$ and $\alpha-\beta<1$, then by Lemma 2 (b)

$$
\sum_{m=1}^{n}\left|a_{m}\right| m^{1}=\sum_{1}^{n}\left|b_{m}\right| m^{1-\alpha}=O\left(n^{\beta-\alpha+1}\right) .
$$

Thus, utilizing Theorem 4 (b) with $\delta=\beta-\alpha+1$, we obtain

$$
G_{\alpha}(t) \in \operatorname{Lip}[1-(\beta-\alpha+1)]=\operatorname{Lip}(\alpha-\beta) \text {. }
$$

$[0,2 \pi]$.

CoRollary 1. (a) $\sum_{m=1}^{\infty}\left|\int_{0}^{t} \sin m x d x\right|^{\alpha} \in \operatorname{Lip}(\alpha-1), 1<\alpha<2$, on (b) If $1<\alpha<2$ and $\left\{w_{m}(x)\right\}$ and $\left\{r_{m}(x)\right\}=\left\{r_{1}\left(2^{m-1} x\right)\right\}$ denote the Walsh and Rademacher functions (defined in [1]), then

$$
\sum_{m=0}^{\infty}\left|\int_{0}^{t} w_{m}(x) d x\right|^{\alpha}=t^{\alpha}+\sum_{m=1}^{\infty} 2^{m-1}\left|\int_{0}^{t} r_{m}(x) d x\right|^{\alpha} \in \operatorname{Lip}(\alpha-1) \text { on }[0,1],
$$

since $\left|\int_{0}^{t} w_{m}(x) d x\right|=\left|\int_{0}^{t} r_{k}(x) d x\right|$ for $2^{k-1} \leqq m<2^{k}, k=1,2, \cdots$, as can be easily seen directly.

(c) If $0<\alpha<2$ and $\left\{h_{m}\right\}$ denotes the Haar system (defined in [1]), then

$$
\sum_{m=0}^{\infty}\left|\int_{0}^{t} h_{m}(x) d x\right|^{\alpha}=t^{\alpha}+\sum_{m=1}^{\infty} 2^{(m-1) \alpha / 2}\left|\int_{0}^{t} r_{m}(x) d x\right|^{\alpha} \in \operatorname{Lip}(\alpha / 2) \text { on }[0,1],
$$

since $\sum_{m=2^{k-1}}^{2^{k}-1}\left|\int_{0}^{t} h_{m}(x) d x\right|=2^{(k-1) \alpha / 2}\left|\int_{0}^{t} r_{k}(x) d x\right|$ for $k=1,2, \cdots$

REMaRk 3. For the Haar system $F_{1}(t)$ has no finite derivative anywhere [5, p. 279].

THEOREM 6. Let $0<\|\varphi\|_{1}<\infty, \varphi_{m}(x)=\varphi(m x)$, and assume $\Phi_{1}(t)$ is of period $b-a$.

(a) $\sum\left|a_{m}\right| m^{-\alpha}<\infty$ if and only if $\sum\left|a_{m}\right|\left|\Phi_{m}(t)\right|^{\alpha} \in L^{1}[a, b]$.

(b) If $\sum\left|a_{m}\right| m^{-\alpha}=\infty$, then $\sum\left|a_{m}\right|\left|\Phi_{m}(t)\right|^{\alpha}=\infty$ almost everywhere.

Proof. Part (a). Since $\Phi_{m}(t)=m^{-1} \Phi_{1}(m t)$, we obtain

$$
\int_{a}^{b}\left|\Phi_{m}(t)\right|^{\alpha} d t=m^{-\alpha} \int_{a}^{b}\left|\Phi_{1}(m t)\right|^{\alpha} d t=m^{-\alpha} \int_{a}^{b}\left|\Phi_{1}(t)\right|^{\alpha} d t
$$

Part (b). Applying Fejer's Lemma [7, p. 49], we obtain for every set $E$ of positive measure 


$$
\lim \int_{E}|\Phi(m t)|^{\alpha} d t=\frac{\mu(E)}{b-a} \int_{a}^{b}\left|\Phi_{1}(t)\right|^{\alpha} d t>0 \quad \text { as } \quad m \rightarrow \infty
$$

and so by a theorem of Orlicz [1, p. 327]

$$
\sum\left|a_{m}\right| m^{-\alpha}\left|\Phi_{1}(m t)\right|^{\alpha}=\sum\left|a_{m}\right|\left|\Phi_{m}(t)\right|^{\alpha}=\infty
$$

almost everywhere.

COROLLARY 2. There exists an absolutely continuous function whose Walsh-Fourier series is absolutely divergent.

Proof. For the Walsh system $F_{1}(t) \notin L^{\infty}$ by Theorem 6 and so the result follows from Theorem A.

It now seems appropriate to prove

THEOREM 7. Let

$$
\omega^{2}(\delta, f)=\sup _{0<h \leqq \delta}\left\{\int_{0}^{1}[f(x+h)-f(x)]^{2} d x\right\}^{1 / 2}
$$

If $\sum 2^{n / 2} \omega^{2}\left(2^{-n}, f\right)<\infty$, then the Walsh-Fourier series of $f$ converges absolutely.

Proof. Let $\left\{c_{n}\right\}$ denote the Walsh-Fourier coefficients of $f$ and let $x+y=\sum_{n=1}^{\infty}\left|x_{n}-y_{n}\right| 2^{-n}$ where $x=\sum x_{n} 2^{-n}$ and $y=\sum y_{n} 2^{-n}$ are the binary expansions of $x$ and $y$ (where for dyadic rationals we choose the finite expansion). N. Fine proved [4, p. 395]

$$
\sum_{k=2^{n-1}}^{2^{n-1}} c_{k}^{2} \leqq \int_{0}^{1}\left[f\left(x+2^{-n}\right)-f(x)\right]^{2} d x
$$

Also, by definition of $\dot{+}$, we obtain

$$
\begin{aligned}
& \int_{0}^{1}\left[f\left(x+2^{-n}\right)-f(x)\right]^{2} d x \\
& \quad=\int_{E_{0}}\left[f\left(x+2^{-n}\right)-f(x)\right]^{2} d x+\int_{E_{1}}\left[f\left(x-2^{-n}\right)-f(x)\right]^{2} d x \\
& \quad=2 \int_{E_{0}}\left[f\left(x+2^{-n}\right)-f(x)\right]^{2} d x
\end{aligned}
$$

where $E_{p}=\left\{x \in[0,1]: x_{n}=p\right\}$ for $p=0,1$. Hence,

$$
\sum_{2^{n-1}}^{2^{n-1}} c_{k}^{2} \leqq 2\left[\omega^{2}\left(2^{-n}, f\right)\right]^{2}
$$

and so by Schwarz's inequality

$$
\sum_{k=2^{n-1}}^{2^{n}-1}\left|c_{k}\right| \leqq\left(\sum_{2^{n-1}}^{2^{n}-1} c_{k}^{2}\right)^{1 / 2}\left(\sum_{2^{n-1}}^{2^{n}-1} 1\right)^{1 / 2} \leqq \omega^{2}\left(2^{-n}, f\right) 2^{n / 2}
$$


Remark 4. Previously N. Fine [4, p. 394] and N. Vilenkin [6, p. 32] proved that if $f \in \operatorname{Lip} \alpha, \alpha>1 / 2$, then the Walsh-Fourier series of $f$ converges absolutely. By Theorem 7 it follows that all of the sufficiency theorems on absolute convergence for trigonometric series [2, p. 154-161] in terms of modulus of continuity carry over completely for the Walsh system.

\section{REFERENCES}

1. G. Alexits, Convergence Problems of Orthogonal Series, Pergamon Press, New York, 1961.

2. N. Bary, A, Treatise on Trigonometric Series, Vol. 2, Pergamon Press, New York, 1964.

3. L. S. Bosanquet and H. Kestelman, Proc. London Math. Soc., 45 (1938), 88-97.

4. N. J. Fine, On the Walsh functions, Trans. Amer. Math. Soc., 65 (1949), 372-414.

5. J. R. McLaughlin, Functions represented by integrated Rademacher series, Coll. Math., 20 (1969), 277-286.

6. N. Vilenkin, On a class of orthonormal systems, Izv. Akad. Nauk SSSR Ser. Mat. 11 (1947), 363-400; English trans., Amer. Math. Soc. Transl. (2) 28 (1963) 1-35.

7. A. Zygmund, Trigonometric series, Vol. 1, Cambridge Univ. Press, New York, 1959.

Received February 25, 1971 and in revised form April 24, 1972. Supported by NSF grant GP-14135.

Pennsylvania State University 



\section{PACIFIC JOURNAL OF MATHEMATICS}

\section{EDITORS}

\author{
H. SAMELSON \\ Stanford University \\ Stanford, California 94305 \\ C. R. HOBBY \\ University of Washington \\ Seattle, Washington 98105
}

\section{J. DuGundJI}

Department of Mathematics University of Southern California Los Angeles, California 90007

RICHARD ARENS

University of California

Los Angeles, California 90024

\section{ASSOCIATE EDITORS}
E. F. BECKENBACH
B. H. NeumanN
F. WOLF
K. YOSHIDA

\section{SUPPORTING INSTITUTIONS}

\author{
UNIVERSITY OF BRITISH COLUMBIA \\ CALIFORNIA INSTITUTE OF TECHNOLOGY \\ UNIVERSITY OF CALIFORNIA \\ MONTANA STATE UNIVERSITY \\ UNIVERSITY OF NEVADA \\ NEW MEXICO STATE UNIVERSITY \\ OREGON STATE UNIVERSITY \\ UNIVERSITY OF OREGON \\ OSAKA UNIVERSITY
}

\author{
UNIVERSITY OF SOUTHERN CALIFORNIA \\ STANFORD UNIVERSITY \\ UNIVERSITY OF TOKYO \\ UNIVERSITY OF UTAH \\ WASHINGTON STATE UNIVERSITY \\ UNIVERSITY OF WASHINGTON \\ AMERICAN MATHEMATICAL SOCIETY \\ NAVAL WEAPONS CENTER
}

The Supporting Institutions listed above contribute to the cost of publication of this Journal, but they are not owners or publishers and have no responsibility for its content or policies.

Mathematical papers intended for publication in the Pacific Journal of Mathematics should be in typed form or offset-reproduced, (not dittoed), double spaced with large margins. Underline Greek letters in red, German in green, and script in blue. The first paragraph or two must be capable of being used separately as a synopsis of the entire paper. The editorial "we" must not be used in the synopsis, and items of the bibliography should not be cited there unless absolutely necessary, in which case they must be identified by author and Journal, rather than by item number. Manuscripts, in duplicate if possible, may be sent to any one of the four editors. Please classify according to the scheme of Math. Rev. Index to Vol. 39. All other communications to the editors should be addressed to the managing editor, Richard Arens, University of California, Los Angeles, California, 90024.

50 reprints are provided free for each article; additional copies may be obtained at cost in multiples of 50 .

The Pacific Journal of Mathematics is published monthly. Effective with Volume 16 the price per volume (3 numbers) is $\$ 8.00$; single issues, $\$ 3.00$. Special price for current issues to individual faculty members of supporting institutions and to individual members of the American Mathematical Society: $\$ 4.00$ per volume; single issues $\$ 1.50$. Back numbers are available.

Subscriptions, orders for back numbers, and changes of address should be sent to Pacific Journal of Mathematics, 103 Highland Boulevard, Berkeley, California, 94708.

PUBLISHED BY PACIFIC JOURNAL OF MATHEMATICS, A NON-PROFIT CORPORATION

Printed at Kokusai Bunken Insatsusha (International Academic Printing Co., Ltd.), 270, 3-chome Totsuka-cho, Shinjuku-ku, Tokyo 160, Japan. 


\section{Pacific Journal of Mathematics}

\section{Vol. 42, No. $2 \quad$ February, 1972}

Stephen Richard Bernfeld, The extendability of solutions of perturbed scalar differential equations ................................. 277

James Edwin Brink, Inequalities involving $f_{-} p$ and $f^{(n)}{ }_{q}$ for $f$ with $n$

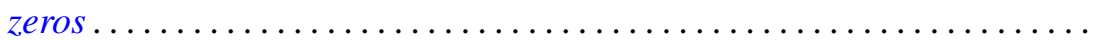

Orrin Frink and Robert S. Smith, On the distributivity of the lattice of filters of a groupoid

Donald Goldsmith, On the density of certain cohesive basic sequences .... 323

Charles Lemuel Hagopian, Planar images of decomposable continua . . . . . 329

W. N. Hudson, A decomposition theorem for biadditive processes ........ 333

W. N. Hudson, Continuity of sample functions of biadditive processes......

Masako Izumi and Shin-ichi Izumi, Integrability of trigonometric series.

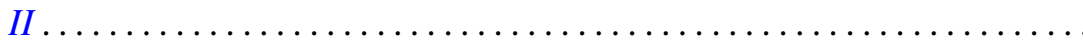

H. M. Ko, Fixed point theorems for point-to-set mappings and the set of

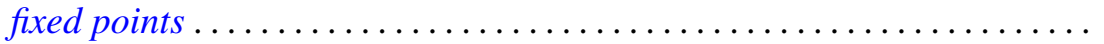

Gregers Louis Krabbe, An algebra of generalized functions on an open interval: two-sided operational calculus ...

Thomas Latimer Kriete, III, Complete non-selfadjointness of almost selfadjoint operators.................................

Shiva Narain Lal and Siya Ram, On the absolute Hausdorff summability of a Fourier series .

Ronald Leslie Lipsman, Representation theory of almost connected groups...

James R. McLaughlin, Integrated orthonormal series.... . .

H. Minc, On permanents of circulants.

Akihiro Okuyama, On a generalization of $\Sigma$-spaces.....

Norberto Salinas, Invariant subspaces and operators of class $(S)$

James D. Stafney, The spectrum of certain lower triangular matrices as operators on the $l_{p}$ spaces .......................

Arne Stray, Interpolation by analytic functions

$\mathrm{Li} \mathrm{Pi} \mathrm{Su}$, Rings of analytic functions on any subset of the complex plane.

R. J. Tondra, A property of manifolds compactly equivalent to compact manifolds.... 